\title{
SEROPREVALENCE OF HEPATITIS E AMONG HOSPITALIZED PATIENTS IN SLOVAKIA: FIRST REPORT
}

\author{
Zuzana Paraličová1, Monika Halánová2, Ivan Schréter ${ }^{1}$, Zuzana Kalinová2 ${ }^{2}$ Martin Novotný1, Jakub Sekula1, \\ Ján Paralič ${ }^{3}$, Pavol Kristian ${ }^{1}$
}

${ }^{1}$ Department of Infectology and Travel Medicine, Faculty of Medicine, Pavol Jozef Šafárik University and Louis Pasteur University Hospital, Košice, Slovak Republic

2Department of Epidemiology, Faculty of Medicine, Pavol Jozef Šafárik University, Košice, Slovak Republic

${ }^{3}$ Department of Cybernetics and Artificial Intelligence, Faculty of Electrical Engineering and Informatics, Technical University of Košice, Košice, Slovak Republic

\section{SUMMARY}

Objective: Hepatitis $\mathrm{E}$ infection is one of the most frequent acute hepatitis in the world. Currently five human genotypes with different geographical distributions and distinct epidemiologic patterns are identified. In Slovakia, only rare cases of hepatitis E have been reported in recent years. Therefore, the aim of the study was to evaluate the prevalence of anti-HEV total antibodies and the main risk factors for HEV in the general population in Eastern Slovakia.

Methods: Detection of anti-HEV total antibodies samples was done by a commercial enzyme-linked immunosorbent assay (ELISA) kit.

Results: Of 175 hospitalized patients included in the study, $76(43.5 \%)$ showed positivity for anti-HEV total antibodies. No statistically significant differences were found in anti-HEV positivity between men and women or in the groups of different living areas (town/village - urban/rural).

Conclusion: Prevalence of anti-HEV total antibodies of hospitalised patients was high. The risk factor significantly associated with antibody positivity was eating raw meat. Other factors, such as sex, age, living area and contact with animals were not associated with antibody positivity.

Key words: hepatitis E, seroprevalence, hospitalized patients, Slovakia

Address for correspondence: P. Kristian, Department of Infectology and Travel Medicine, Faculty of Medicine, Pavol Jozef Šafárik University, Rastislavova 43, 04190 Košice, Slovak Republic. E-mail: kristian@unlp.sk

https://doi.org/10.21101/cejph.a5346

\section{INTRODUCTION}

Hepatitis E is a disease known since the 1980 s, and many new facts about the disease and its causative agent have been discovered in recent years. Hepatitis E virus (HEV) is an RNA virus, the only member of the genus Hepevirus in the Hepeviridae family (1).

Five human genotypes are currently recognised - HEV 1 to 4 and HEV 7 - based on the nucleotide sequences of the genome. Various HEV genotypes have different geographical distributions, distinct epidemiologic patterns and even some differences in clinical manifestation.

Genotype 1, which has five subtypes $(1 \mathrm{a}-1 \mathrm{e})$, causes the majority of human infections. It occurs mainly in tropical and subtropical countries with low hygiene and sanitary conditions, particularly in Southeast Asia and Africa, where it can cause sporadic disease but also widespread epidemics that occur after faecal contamination of drinking water (2). The incidence of hepatitis $E$ in areas in which HEV genotype 1 is endemic is estimated to be 3.3 million cases per year (3). Genotype 2, with two subtypes (2a, 2b), has a similar geographic distribution but is much less common. Both genotype 1 and genotype 2 infect humans only, and the infection is spread via the faecal-oral route.

Genotypes 3, 4, and 7 are less virulent than genotypes 1 and 2 (4). They have a zoonotic character; human infections can occur after direct contact with infected animals but mainly indirectly via the consumption of raw pig meat, liver and sausages. Genotype 3 ( 10 subtypes, $3 \mathrm{a}-3 \mathrm{j}$ ), with worldwide distribution, has been found in pigs and other animals (deer, wild boar, rodents, molluscs) in Europe, Asia and the Americas, and causes sporadic autochthonous diseases in humans. Genotype 4, with seven subtypes $(4 a-4 g)$, is relatively rare, occurring in East Asia, mainly in Taiwan and China (5). Genotype 7 has been identified in dromedary camels from the Middle East and in an immunocompromised transplant patient who regularly consumed camel milk and meat (6).

Hepatitis E is an acute "self-limiting" disease that varies in severity from inapparent to fulminant. Most infections have a mild, subclinical course, mainly in children, whose clinical symptoms are rare (7). The disease is indistinguishable from acute hepatitis A without serological evidence, but overall it has a slightly higher mortality of $1-4 \%$. Differences have been observed in 
the diseases caused by different genotypes. Genotypes 3, 4 and 7 more often affect people over 40 years of age and people with impaired immunity as well. Genotypes 1 and 2 are more likely to affect younger persons (8).

The seroprevalence of hepatitis $\mathrm{E}$ antibodies has significant geographic differences. It ranges from $10-40 \%$ in endemic areas, but in some regions of Asia it reaches more than $60 \%(5,9)$. The seroprevalence anti-HEV IgG in Europe varies between and within countries. The results of a meta-analysis published by Hartl et al. showed a prevalence in different European countries from 0.6 to $52.5 \%$, increasing with age. The seroprevalence of the general population also varied depending on the assays used (10).

The diagnosis of acute hepatitis $\mathrm{E}$ is based on detection of anti-HEV IgM antibodies, directed against a range of recombinant viral antigens by enzyme immunoassay or rapid immunochromatographic kits. Comparative studies show that these tests differ substantially in their accuracy, and users should ensure that a test used has been validated in their population (11). The determination of immunity after previous exposure to HEV by detection of anti-HEV IgG antibodies is more problematic. Available enzyme immunoassays use different antigens and vary in their effectiveness (12).

In Slovakia, only rare cases of imported hepatitis $\mathrm{E}$ have been reported in recent years. The first cases of autochthonous hepatitis E were reported in 2013, and to date only 83 autochthonous diseases have been reported (13). Therefore, the aim of the study was to evaluate the prevalence of anti-HEV total antibodies and the main risk factors for $\mathrm{HEV}$ in the general population in Eastern Slovakia.

\section{MATERIAL AND METHODS}

\section{Study Population}

A total of 175 patients (66 men, 109 women) hospitalised at the Department of Infectology and Travel Medicine (DITM) of the Louis Pasteur University Hospital in Košice, Slovakia, within the two-month period (February - March) were examined for the presence of anti-HEV total antibodies. Those examined were aged 19-94 years (median age 48.3 years). Eleven (6\%) patients were of Roma origin.

Every patient filled in a questionnaire to assess the possible risk factors for contracting HEV, including place of residence (town/ village), contact with animals (domestic/wild), consumption of raw/undercooked meat, liver diseases in the patient's history, ethnicity, and travel to tropical countries.

The study was performed in accordance with the principles of the Declaration of Helsinki and approved by the Ethics Committee of Luis Pasteur University Hospital in Košice. Participation in the study was fully voluntary and anonymous and written informed consent was obtained from each person prior to the medical examination.

\section{Samples}

Collection of venous blood was performed under standard conditions from a peripheral vein in the antecubital fossa. After centrifugation of the blood, serum samples were collected and stored at $-70{ }^{\circ} \mathrm{C}$ until their use in the serological test.

\section{Serological Examination}

Detection of anti-HEV total antibodies samples was done by a commercial enzyme-linked immunosorbent assay (ELISA) kit (DRG Instruments $\mathrm{GmbH}$, Germany), according to the manufacturer's instructions. The test is determined for the qualitative determination of total antibodies (mostly $\operatorname{IgG}, \operatorname{IgM}$ and $\operatorname{IgA}$ ) to hepatitis E virus in serum.

\section{Statistical Analysis}

Statistical analysis tests were calculated only in the case of patients with positive or negative results for anti-HEV total. The association between the possible risk factors and HEV infection was estimated by means of Pearson's chi-squared test, except for two risk factors (travelling to tropical countries and Roma people), where we had a smaller number of patients available; in those cases Fisher's exact test was used. In both cases, we have chosen the significance level 0.05 for the $\mathrm{p}$-value associated with the respective test statistic.

\section{RESULTS}

Of 175 hospitalized patients included in the study, 76 (43.5\%) showed positivity for anti-HEV total antibodies, and $79(45 \%)$ were negative. Another $20(11.5 \%)$ patients gave an indeterminate anti-HEV total result; therefore, these people were excluded from further statistical analysis of HEV-seropositivity issues, and statistical analysis tests were calculated in patients with positive (76) or negative (79) results for anti-HEV total antibodies only.

Of the 175 examined patients six were hospitalized for acute viral hepatitis, but acute hepatitis E was not confirmed in any of them. No statistically significant differences were found in anti-HEV positivity between men and women, between different age categories, or in the groups with different living areas (town/ village - urban/rural). Also, the relationship between people who had regular contact with animals in general, or contact with pigs, dogs, or poultry was not statistically significant. Statistically significant differences were not confirmed for visiting tropical countries in the past and between groups of Roma and non-Roma people. Statistically significant differences were found for the consumption of raw/uncooked meat $(p=0.047)$ only (Table 1$)$.

\section{DISCUSSION}

Viral hepatitis E infection has worldwide distribution and is a global cause for morbidity and mortality. The course of viral hepatitis E has two phases, the prodromal phase and the icteric phase, and clinical symptoms are indistinguishable from other types of acute viral hepatitis (14). Also, in the nonendemic (autochthonous) type of acute hepatitis $\mathrm{E}$ infection, the majority of patients have subclinical manifestations and mild symptoms. Therefore, for definitive diagnosis, a laboratory examination based on identification of HEV RNA by the molecular PCR 
Table 1. Association between potential risk factors and HEV infection by means of Pearson's chi-squared test $(N=175)$

\begin{tabular}{|c|c|c|c|c|c|c|c|}
\hline & & \multirow{2}{*}{$\begin{array}{c}\text { Tested } \\
\mathbf{n}\end{array}$} & \multicolumn{2}{|c|}{ Anti-HEV+ } & \multicolumn{3}{|c|}{ Pearson's chi-squared test } \\
\hline & & & $\begin{array}{c}\mathrm{HEV}=\mathrm{N} \\
\mathrm{n}\end{array}$ & $\begin{array}{c}\mathrm{HEV}=\mathrm{P} \\
\mathrm{n}\end{array}$ & $x^{2}$ & $p$-value & df \\
\hline \multirow{2}{*}{ Sex } & Male & 66 & 25 & 30 & \multirow{2}{*}{1.0369} & \multirow{2}{*}{0.3086} & \multirow{2}{*}{1} \\
\hline & Female & 109 & 54 & 46 & & & \\
\hline \multirow{6}{*}{ Age group (years) } & $19-25$ & 34 & 17 & 12 & \multirow{6}{*}{1.8583} & \multirow{6}{*}{0.8684} & \multirow{6}{*}{5} \\
\hline & $26-35$ & 35 & 16 & 15 & & & \\
\hline & $36-45$ & 20 & 11 & 8 & & & \\
\hline & $46-55$ & 16 & 6 & 8 & & & \\
\hline & $56-65$ & 23 & 9 & 10 & & & \\
\hline & $>65$ & 47 & 20 & 23 & & & \\
\hline \multirow{2}{*}{ Place of living } & Town & 115 & 50 & 50 & \multirow{2}{*}{0.1056} & \multirow{2}{*}{0.7452} & \multirow{2}{*}{1} \\
\hline & Village & 60 & 29 & 26 & & & \\
\hline \multirow{2}{*}{$\begin{array}{l}\text { Contact with } \\
\text { animals }\end{array}$} & Yes & 102 & 46 & 50 & \multirow{2}{*}{0.9395} & \multirow{2}{*}{0.3324} & \multirow{2}{*}{1} \\
\hline & No & 73 & 33 & 26 & & & \\
\hline \multirow{2}{*}{$\begin{array}{l}\text { Contact with do- } \\
\text { mestic animals }\end{array}$} & Yes & 80 & 35 & 40 & \multirow{2}{*}{1.0757} & \multirow{2}{*}{0.2997} & \multirow{2}{*}{1} \\
\hline & No & 95 & 44 & 36 & & & \\
\hline \multirow{2}{*}{$\begin{array}{l}\text { Contact with } \\
\text { animals in the past }\end{array}$} & Yes & 38 & 15 & 21 & \multirow{2}{*}{1.6232} & \multirow{2}{*}{0.2026} & \multirow{2}{*}{1} \\
\hline & No & 137 & 64 & 55 & & & \\
\hline \multirow{2}{*}{ Eating raw meat } & Yes & 48 & 17 & 27 & \multirow{2}{*}{3.9533} & \multirow{2}{*}{$0.0468^{*}$} & \multirow{2}{*}{1} \\
\hline & No & 127 & 62 & 48 & & & \\
\hline \multirow{2}{*}{$\begin{array}{l}\text { Liver disease in } \\
\text { patient's history }\end{array}$} & Yes & 27 & 11 & 12 & 01078 & 07127 & 1 \\
\hline & No & 146 & 67 & 63 & 0.1010 & $0.14 \angle 1$ & 1 \\
\hline & & & & & & $\begin{array}{l}\text { r's exact } \\
p \text {-value }\end{array}$ & \\
\hline Travelling to tropical & Yes & 28 & 15 & 8 & & 01765 & \\
\hline countries & No & 146 & 64 & 68 & & 0.1700 & \\
\hline Roma orinin & Yes & 11 & 5 & 5 & & 1 & \\
\hline Roma ongin & No & 164 & 74 & 71 & & 1 & \\
\hline
\end{tabular}

${ }^{*} p<0.05$

method or identification of anti-HEV Ig by the serological method ELISA is necessary. Anti-HEV IgM are present during the acute phase of the infection, and they can be detected in the serum for 3-8 months. Anti-HEV IgG start being detected shortly after the increasing of $\operatorname{IgM}$ and persist in the serum for 1-14 years after the infection (on average 4.5 years) $(15,16)$. A positive anti-HEV IgG usually suggests past infection.

In our study, we examined patients hospitalized at DITM in Košice, the largest city in the Eastern part of Slovakia, with approximately 250,000 inhabitants. Adult patients aged 19 years and older are hospitalised at the DITM. The spectrum of patients approximately corresponds to a representative sample of the general population. Positive anti-HEV total antibodies were detected in 76 out of 175 examined people, which means up to $43.5 \%$ of serum samples tested. Up to now, only 83 autochthonous diseases have been officially reported in Slovakia. This number is much less in comparison with the neighbouring Czech Republic, where 412 cases were reported in 2015 and 339 in 2016. Estimated seroprevalence of anti-HEV IgG in the Czech Republic is $12.9 \%$ (10). Similar studies from Slovakia have not yet been published.
As this is the first study on the prevalence of anti-HEV in Slovakia, we cannot compare whether such a high prevalence concerns only the region of Eastern Slovakia or the whole of Slovakia.

A serological survey from neighbouring Central European countries shows lower seroprevalence of anti-HEV IgG. In the Czech Republic, the determined prevalence of hepatitis E IgG antibodies in two different studies was $5.7 \%$ and $6.7 \%$, respectively (17). Recalculated for the general population of the Czech Republic, the estimated prevalence was $8.6 \%$ (18). In one Polish study the determined prevalence of hepatitis E IgG antibodies among 182 patients was $15.9 \%$ (19). Hepatitis E seroprevalence data from Hungary are not published, but the disease is endemic there, with 166 reported cases in 2015 (20).

Similarly to our results, a high prevalence of anti-HEV IgG was found in blood donors in central Italy, where overall prevalence was $49 \%$ (153/313) of all tested blood donors. Eating raw dried pig-liver sausage was the only independent predictor of $\mathrm{HEV}$ infection in their study, in which serum samples were tested using commercial ELISA kits (Wantai, Biologic Pharmacy Enterprise, 
Beijing, China), (21). Great differences in the prevalence of antiHEV have been found depending on which assay was used. In a Danish study, Holm et al. tested 504 consecutive blood donors for anti-HEV IgG in both the NIH assay and the Wantai assay. Using the NIH assay $10.7 \%$ were reactive for anti-HEV IgG vs. $19.8 \%$ reactive donors using the Wantai assay. All 54 anti-HEVpositive donors in the NIH assay were reactive when using the Wantai assay (22). In a Swedish study, 500 blood donors and 316 patients were analysed with five different assays for anti-HEV IgM and IgG. Concordant results for IgM and IgG with all assays were obtained for only $71 \%$ and $70 \%$ of patients with suspected hepatitis E, respectively. The range of sensitivity for anti-HEV detection was broad - from $42 \%$ to $96 \%$. The Axiom and DiaPro were the most sensitive assays (23). In another study from the Netherlands comparing 8 different anti-HEV assays, the DSI and Wantai IgG were the most sensitive assays (24).

Our study has some limitations. One important limitation is the small number of study participants and only from one region of Slovakia. Another important limitation is that data were collected from patients hospitalized in the Department of Infectious Diseases, which may not reflect the general population. However, we do not expect that seroprevalence has been increased by acute viral hepatitis, because only 6 of tested patients had acute hepatitis, no one had acute hepatitis E, and anti-HEV IgG was positive only in one of them. The third limitation is that only one diagnostic test has been used. These limitations might have influenced the final results. To obtain more precise data on the seroprevalence of $\mathrm{HEV}$ in Slovakia large-scale studies from each region of Slovakia and different population groups are needed.

\section{CONCLUSION}

Based on our obtained results, we can conclude that the prevalence of anti-HEV total antibodies of hospitalised patients was high. The risk factor significantly associated with antibody positivity was eating raw meat. Other factors, such as sex, living area and contact with animals were not associated with antibody positivity.

\section{Acknowledgement}

The study was supported by the Slovak Grant Committee VEGA, no. $1 / 0084 / 18$.

\section{Conflict of Interests}

None declared

\section{REFERENCES}

1. Meng XJ, Anderson DA, Arankalle VA, Emerson SU, Harrison TJ, Jameel S, et al. Hepeviridae. In: King AMQ, Adams MJ, Carstens EB, Lefkowitz EJ, editors. Virus taxonomy: ninth report of the International Committee on Taxonomy of Viruses. London: Elsevier Academic Press; 2012. p. 1021-8.

2. Aggarwal R, Naik S. Epidemiology of hepatitis E: current status. J Gastroenterol Hepatol. 2009;24(9):1484-93

3. Rein DB, Stevens GA, Theaker J, Wittenborn JS, Wiersma ST. The global burden of hepatitis E virus genotypes 1 and 2 in 2005. Hepatology. 2012;55(4):988-97.

4. Purcell RH, Emerson SU. Hepatitis E: an emerging awareness of an old disease. J Hepatol. 2008;48(3):494-503.
5. World Health Organization. The global prevalence of hepatitis E virus infection and susceptibility: a systematic review. Geneva: WHO; 2010.

6. Lee GH, Tan BH, Teo ECY, Lim SG, Dan YY, Wee A, et al. Chronic infection with camelid hepatitis $\mathrm{E}$ virus in a liver transplant recipient who regularly consumes camel meat and milk. Gastroenterology. 2016;150(2):355-7.

7. Wedemeyer H, Pischke S, Manns MP. Pathogenesis and treatment of hepatitis E virus infection. Gastroenterology. 2012;142(6):1388-97.

8. Mushahwar IK. Hepatitis E virus: molecular virology, clinical features, diagnosis, transmission, epidemiology, and prevention. J Med Virol. 2008;80(4):646-58.

9. Anderson DA. Hepatitis E virus. In: Mandell GL, Bennett JE, Dolin $\mathrm{R}$, editors. Mandell, Douglas, and Bennett's principles and practice of infectious diseases. 7th ed. Philadelphia: Churchill Livingstone; 2010. p. 2411-21.

10. Hartl J, Otto B, Madden RG, Webb G, Woolson KL, Kriston L, et al. Hepatitis E seroprevalence in Europe: a meta-analysis. Viruses. 2016 Aug 6;8(8):211. doi: 10.3390/v8080211.

11. Kamar N, Bendall R, Legrand-Abravanel F, Xia NS, Ijaz S, Izopet J, et al. Hepatitis E. Lancet. 2012;379(9835):2477-88.

12. Bendall R, Ellis V, Ijaz S, Ali R, Dalton H. A comparison of two commercially available anti-HEV IgG kits and a re-evaluation of anti-HEV IgG seroprevalence data in developed countries. J Med Virol. 2010;82(5):799805.

13. Analysis of the epidemiological situation and activities of Epidemiology divisions in the Slovak Republic in 2016 [Internet]. Public Health Authority of the Slovak Republic [cited 2019 Dec 16]. Available from: https://www.epis.sk/InformacnaCast/Publikacie/VyrocneSpravy/Files/ VS_SR_2016_Aktualizacia100118.aspx. (In Slovak.)

14. Meng XJ. Recent advances in hepatitis E virus. J Viral Hepatol. 2010;17(3):153-61.

15. Kamar N, Dalton HR, Abravanel F, Izopet J. Hepatitis E virus infection. Clin Microbiol Rev. 2014;27(1):116-38.

16. Pérez-Gracia MT, Suay B, Mateos-Lindemann ML. Hepatitis E: an emerging disease. Infect Genet Evol. 2014;22:40-59.

17. Straková P, Kříž B, Rudolf I, Hubálek Z. Seroprevalence study of hepatitis E virus infection in two districts of the Czech Republic. Epidemiol Mikrobiol Imunol. 2014;63(2):92-4.

18. Němeček V, Butovičová P, Malý M, Dítě P, Veřtátová M, Vodičková I, et al. The prevalence of antibodies against Hepatitis E virus in the Czech Republic: serological survey. Epidemiol Mikrobiol Imunol. 2017;66(1):37.

19. Bura M, Michalak M, Chojnicki M, Czajka A, Kowala-Piaskowska A, Mozer-Lisewska I. Seroprevalence of anti-HEV IgG in 182 Polish patients. Postepy Hig Med Dosw. 2015;69:320-6.

20. Adlhoch C, Avellon A, Baylis SA, Ciccaglione AR, Couturier E, de Sousa $R$, et al. Hepatitis E virus: assessment of the epidemiological situation in humans in Europe, 2014/15. J Clin Virol. 2016;82:9-16.

21. Lucarelli C, Spada E, Taliani G, Chionne P, Madonna E, Marcantonio C, et al. High prevalence of anti-hepatitis $\mathrm{E}$ virus antibodies among blood donors in central Italy, February to March 2014. Euro Surveill. 2016 Jul 28;21(30). doi: 10.2807/1560-7917.ES.2016.21.30.30299.

22. Holm DK, Moessner BK, Engle RE, Zaaijer HL, Georgsen J, Purcell $\mathrm{RH}$, et al. Declining prevalence of hepatitis E antibodies among Danish blood donors. Transfusion. 2015;55(7):1662-7.

23. Norder H, Karlsson M, Mellgren Å, Konar J, Sandberg E, Lasson A, et al. Diagnostic performance of five assays for antihepatitis E virus IgG and IgM in n a large cohort study. J Clin Microbiol. 2016;54(3):549-55.

24. Pas SD, Streefkerk RHRA, Pronk M, de Man RA, Beersma MF, Osterhaus $\mathrm{AD}$, et al. Diagnostic performance of selected commercial HEV IgM and IgG ELISAs for immunocompromised and immunocompetent patients. J Clin Virol. 2013;58(4):629-34. 